\title{
A importância da comunicação para a implementação da política nacional de humanização no Hospital Universitário da Universidade de São Paulo
}

The importance of communication for the implementation of the national policy of humanization at the University Hospital of the University of São Paulo

La importancia de la comunicación para la implementación de la política nacional de humanización en el Hospital Universitario de la Universidad de São Paulo

\section{Maria Aparecida da Silva Rodrigues}

- Especialista em Gestão Estratégica em Comunicação Organizacional e Relações Públicas pela Escola de Comunicações e Artes da Universidade de São Paulo (ECA-USP)

- Especialista em Psicologia Hospitalar em Hospital Geral pelo Hospital das Clínicas da Faculdade de Medicina da Universidade de São Paulo (HCFM-USP)

- Graduada em Psicologia pelo Centro Universitário das Faculdades Metropolitanas Unidas (FMU)

- Coordenadora do Serviço de Acolhimento e Humanização do Hospital Universitário da Universidade de São Paulo (HU-USP)

- Membro da Comissão de Acolhimento e Humanização do HU-USP

- Membro do Comitê de Humanização do HCFM-USP

- E-mail: crodrigues@hu.usp.br 


\section{Resumo}

Este artigo discorre sobre um novo paradigma de gestão institucional, baseado na comunicação e no relacionamento. Hoje, em vez do modelo tradicional de comunicação informacional, se passa a enfatizar a comunicação interativa e relacional, ou seja, a gestão participativa. A Política Nacional de Humanização (PNH) proposta pelo Sistema Único de Saúde (SUS), por meio do HumanizaSUS, graças ao princípios ideológicos, organizacionais e de participação social que o norteiam, aumenta o grau de corresponsabilidade dos atores envolvidos, tendo que haver necessariamente uma interação entre usuários, profissionais, gestores e instituições da rede de saúde.

PALAVRAS CHAVES: COMUNICAÇÃO • RELACIONAMENTO • RELAÇÕES PÚBLICAS • POLÍTICA NACIONAL DE HUMANIZAÇÃO • HUMANIZA-SUS

\section{Abstract}

This article presents a new paradigm for institutional management. Communication and relationships are their main protagonists. The traditional model of informational communication is changed by an emphasis on interactive and relational communication. The National Policy of Humanization proposed by the Unified Health System (SUS), through the HumaniSUS, starts from it's ideological principles, organizational, and social participation, increasing the degree of responsibility of the actors involved in the health system. It becomes necessary an interaction between users, professionals, managers and the health institutions network.

KEYWORDS: COMMUNICATION • RELATIONSHIP • PUBLIC RELATIONS • NATIONAL POLICY OF HUMANIZATION • HUMANIZA-SUS

\section{Resumen}

Este artículo discurre sobre un nuevo paradigma de gestión institucional, sustentado en la comunicación y en el relacionamiento. Hoy, al contrario del modelo tradicional de comunicación informacional, se pasa a enfatizar la comunicación interactiva y relacional, es decir, la gestión participativa. La Política Nacional de Humanización propuesta por el Sistema Único de Salud (SUS), a través del HumanizaSUS, gracias a los principios ideológicos, organizacionales e de participación social que lo nortean, aumenta el grado de co-responsabilidad de los actores involucrados, existiendo necesariamente una interacción entre los usuarios, profesionales, gestores e instituciones de la red de salud.

PALABRAS CLAVE: COMUNICACIÓN • RELACIONAMIENTO • RELACIONES PÚBLICAS • POLÍTICA NACIONAL DE HUMANIZACIÓN・HUMANIZA-SUS 
$\Delta$ principal razão motivadora para o desenvolvimento deste trabalho ${ }^{1}$ foi a falta de engajamento dos profissionais do Hospital Universitário da Universidade de São Paulo nas ações de humanização propostas. Considerou-se de fundamental relevância a realização de uma análise de cenário, utilizando a matriz swot, apresentando os pontos fortes e fracos, bem como as oportunidades e ameaças, mostrando o potencial do HU-USP para implementação da Política Nacional de Humanização. O objetivo é a melhoria na qualidade do trabalho desenvolvido, no relacionamento e na comunicação entre os usuários, profissionais e gestores, como também entre as instituições de saúde, possibilitando agregar valor à instituição.

\section{SISTEMA ÚNICO DE SAÚDE - SUS}

O Sistema Único de Saúde (SUS) foi criado pela Constituição Federal de 1988 para que toda a população brasileira tenha acesso ao atendimento público de saúde. Dele fazem parte centros e postos de saúde, hospitais - incluindo os universitários -, laboratórios, hemocentros, além de fundações e institutos de pesquisa.

Antes do advento do SUS, a atuação do Ministério da Saúde se resumia às atividades de promoção de saúde e prevenção de doenças - por exemplo a vacinação, realizada em regime universal. A assistência médico-hospitalar era para poucas doenças; servia aos indigentes, ou seja, a quem não tinha acesso ao atendimento pelo Instituto Nacional de Assistência Médica da Previdência Social (Inamps). Este dispunha de estabelecimentos próprios, mas a maior parte do atendimento era realizado pela iniciativa privada, com os convênios fixando a remuneração por procedimento, consolidando-se a lógica de cuidar da doença e não da saúde.

A Constituição de 1988 foi um marco na história da saúde pública brasileira. Ela incorporou teses da Reforma Sanitária e estabeleceu a saúde "como direito de todos e dever do Estado" (seção II - Da saúde, capítulo II, art. 196). A saúde deve ser garantida por políticas sociais e econômicas, que visem à redução do risco de doença e de outros agravos e ao acesso universal e igualitário às ações e aos serviços para sua promoção, proteção e recuperação (Brasil, 1988).

As ações e os serviços de saúde passaram a ser considerados, assim, de relevância pública, cabendo ao poder público sua regulamentação, sua fiscalização e seu controle. Assim, em 19 de setembro de 1990 ocorreu a regulamentação do SUS, por meio da Lei n. 8080, que conceituou e definiu seus objetivos e suas atribuições, firmando as seguintes diretrizes: 1) descentralização político-administrativa com direção única em cada esfera do governo; 2) universalidade de acesso; 3) integralidade da assistência; 4) equidade; 5) participação da comunidade (Brasil, 1990).

\footnotetext{
${ }^{1}$ Este artigo é fruto do trabalho de conclusão do curso de Pós-Graduação Lato Sensu de Gestão Estratégica em Comunicação Organizacional e Relações Públicas, desenvolvido na Escola de Comunicações e Artes da Universidade de São Paulo, sob orientação da Profa. Dra. Margarida Maria Krohling Kunsch.
} 


\section{POLÍTICA NACIONAL DE HUMANIZAÇÃO - PNH}

A saúde é um bem socialmente valorizado, ao qual as sociedades contemporâneas atribuem crescente importância e que a cada dia conquista maior reconhecimento como direito humano básico, de acordo com o que estabeleceu há várias décadas a Organização Mundial de Saúde (OMS). No entanto, apesar da universalidade de sua valorização e da amplitude do direito humano básico, a realidade nos mostra uma grande heterogeneidade nos níveis e na estrutura de desenvolvimento da proteção à saúde entre as populações de um mesmo país. Pode-se deduzir que a saúde, considerada um direito humano básico, não está distribuída equitativamente pela população, como descrito nos princípios do SUS.

Segundo Dário F. Pasche e Eduardo Passos (2008), a Política Nacional de Humanização (PNH) é uma inflexão do SUS, emergindo da experimentação prática da política pública de saúde, a qual, no curso de duas décadas, foi capaz de enfrentar uma série de desafios, superando-os.

A humanização despontou na forma de política pública em resposta aos reclames da sociedade. Por um lado, consideraram-se os fenômenos culturais da contemporaneidade. Por outro lado, era evidente o sucateamento dos serviços de saúde, devido à má gestão ou aos sempre insuficientes investimentos frente aos crescentes diante dos custos da medicina biotecnológica, das filas intermináveis, do atendimento insatisfatório aos pacientes por profissionais mal remunerados e desvalorizados, além do mais variados conflitos.

No ano 2000, o Ministério da Saúde, sensível às manifestações setoriais e às diversas iniciativas locais de humanização das práticas da saúde, criou o Programa Nacional de Humanização da Assistência Hospitalar (PNHAH). Tratava-se de uma iniciativa que estimulava a disseminação das ideias da humanização, os diagnósticos situacionais e a promoção de ações humanizadoras de acordo com as realidades locais. Inovador e bem construído por um grupo de psicanalistas, o programa tinha forte acento na transformação das relações interpessoais pelo aprofundamento da compreensão de fenômenos no campo da subjetividade.

Na saúde surgiram várias iniciativas com o nome de humanização, como, por exemplo, os acordes da luta antimanicomial na área da saúde mental e os movimentos feministas pela humanização do parto na área da saúde da mulher, que começaram a ganhar volume e a produzir ruído suficiente para deixar marcas na história (Rios, 2009, p. 9).

Em 2003, o Ministério da Saúde fez uma revisão na PNHAH e lançou a Política Nacional de Humanização (PNH), que mudou o patamar de alcance da humanização dos hospitais para toda a rede SUS e definiu uma política cujo foco passaram a ser, principalmente, os processos de gestão e de trabalho. Nesse novo paradigma, Izabel C. Rios (2009, p. 16) aponta que 
a humanização focaliza com especial atenção os processos de trabalho e os modelos de gestão e planejamento, interferindo no cerne da vida institucional, local onde de fato se engendram os vícios e os abusos da violência institucional. O resultado esperado é a valorização das pessoas em todas as práticas de atenção e gestão, a integração, o compromisso e a responsabilidade de todos com o bem comum.

Portanto, um dos maiores desafios desse modelo de gestão participativa é o alinhamento das diversas instâncias institucionais, saindo do modelo fragmentado para um modelo de trabaIho integrado, com uma visão do todo em busca de soluções compartilhadas, valorizando a escuta e a fala.

A PNH reconhece a existência de um SUS que dá certo, mas marcado por desafios e problemas que tornam necessário recuperá-lo, um posicionamento muitas vezes visto como um horizonte utópico.

O SUS é uma conquista do cidadão brasileiro, o que implica coniderar a mobilização ativa dos trabalhadores/colaboradores e usuários/clientes ${ }^{2}$ na busca do seu direito à saúde. A institucionalização das ouvidorias e a pesquisa de satisfação surgem como instrumentos que possibilitam o permanente diálogo e acompanhamento em relação à qualidade de trabalho oferecido pelo SUS.

Pelo que se pode verificar, o tema "humanização" passou a ser discutido amplamente na sociedade, particularmente nos serviços de saúde e nos hospitais, como uma reação ao modelo hegemônico de assistência à saúde, objetivando-se melhor qualidade no atendimento à saúde do usuário e de melhores condições de trabalho para os profissionais. A preocupação com a humanização no ambiente hospitalar tem sido objeto de reflexão e discussão entre profissionais, como também tema constante em debates, congressos e simpósios na sociedade científica.

Segundo Margarida Kunsch (2010, p. 9-13) o tema humanização anuncia uma nova era no contexto das organizações. O paradigma linear-cartesiano, causal, no qual os indivíduos estão submetidos à autoridade e ao controle - como na teoria da administração de Frederick Taylor, por exemplo -, é superado pelo novo paradigma emergente, sistêmico e complexo, que vê a organização como espaço de diálogo e de construção de significado.

Suely Deslandes (2006, p. 35), afirma que "a humanização deve ser praticada, nos serviços de saúde, com profissionais e usuários de forma dialógica, em busca de uma construção de novos caminhos capazes de propiciar um novo paradigma de gestão da saúde pública".

\footnotetext{
${ }_{2}$ Tem sido frequente na literatura o termo cliente/usuário, mas, tratando-se de uma instituição pública, o adequado é utilizar só o termo usuário - identificado como membro da comunidade organizada com direitos e deveres. O SUS migrou de um modelo de seguro de saúde, com benefícios apenas quem paga, para o desenho de seguridade social, direito independente de pagamento, ou seja, remetia a um período histórico confuso de gestão social. Há também a participação da iniciativa privada de forma complementar. Assim, provavelmente são esses os motivos da confusão na utilização da terminologia nas instituições públicas.
} 
Tomando por base as afirmações mencionadas, o novo paradigma mostra a importância do resgate da dimensão humana no contexto institucional. Ele leva a refletir sobre a renovação do estilo de gestão, a importância de uma gestão participativa calcada no diálogo, no respeito ao ser humano, no relacionamento e na questão da ambiência, exigindo uma visão holística, considerando o ambiente interno e seu entorno.

Há por parte Ministério da Saúde (2003) uma atenção especial à questão de humanização dos equipamentos de saúde que mantêm contrato com o SUS. As instituições recebem um incentivo mensal, que fica incorporado ao teto da média complexidade, estabelecido no convênio inicial firmado entre elas e as secretarias estaduais da Saúde.

A política de humanização das secretarias estaduais visa à recuperação do sentido humano nos serviços, considerando a singularidade, propondo uma nova relação entre usuários, redes sociais e trabalhadores, melhorando as relações, apostando no trabalho coletivo, na direção de um SUS acolhedor e resolutivo. Para tanto, incentiva o aumento do grau de corresponsabilidade e de comunicação entre os atores envolvidos na produção de saúde (MS, 2004).

A implementação de uma nova política em uma instituição é algo bastante complexo, exigindo quebra de paradigma e mudança de comportamento e de atitudes. É necessário promover ações estrategicamente planejadas, o desenvolvimento de um trabalho sistêmico e contínuo, um processo de educação permanente e a formação de agentes multiplicadores de informação, pessoas-chave no processo de mudança de cultura na instituição.

\section{COMUNICAÇÃO}

A comunicação é um processo ligado a uma matriz comum: a vida em sociedade. $\mathrm{O}$ ato de comunicar envolve intercambiar pensamentos, sentimentos, informações, sendo, assim, um confronto de idéias. É a base das relações humanas e permite que as significações (mensagens) sejam transmitidas entre as pessoas ou os grupos, das mais variadas formas.

Nas organizações a comunicação é essencial no apoio a uma gestão eficaz. No caso das instituições hospitalares, além disso, ela contribui fundamentalmente para um atendimento humanizado, seja na prevenção, no processo de cura, na reabilitação ou na promoção da saúde. Nesse sentido, a comunicação eficiente atribui significado, transmite credibilidade, facilitando o processo de efetiva aderência ao tratamento.

A escolha dos meios de comunicação e a utilização dos suportes disponíveis devem ser observados de modo a facilitar todo o processo, com o menor índice de ruídos possíveis. 
No ambiente institucional/organizacional existem dois tipos de comunicação: a formal e a informal. Uma organização não pode sobreviver sem a comunicação e para eficácia do processo é preciso que os dois tipos de comunicação - formal e informal - sejam avaliados com atenção.

Segundo Sidinéia G. Freitas (2006), para realmente conhecer a instituição/organização, o comunicador deve ir além da rede formal e do discurso, unindo com este as atitudes, observando as ações e os comportamentos. É exatamente no informal que o indivíduo se caracteriza como persona. Para Kunsch (2003, p. 72), as organizações precisam

levar em conta os aspectos relacionais, os contextos, os condicionamentos internos e externos, bem como a complexidade que permeia todo o processo comunicativo. Daí a necessidade de ultrapassarmos a visão meramente mecanicista da comunicação para outra mais interpretativa e crítica.

Como afirma James Grunig (2009), as organizações mantêm relacionamento com sua "família" de colaboradores, com as comunidades, com os governos, consumidores, investidores, patrocinadores e grupos de pressão, entre outros públicos. Portanto, as organizações precisam das relações públicas porque mantêm relacionamento com seus públicos. Sendo a comunicação um processo contínuo, é uma das formas mais eficazes de negociação e colaboração.

Assim, o profissional de relações públicas, com o objetivo de compreender melhor a cultura da instituição/organização, deverá estar sempre atento a todo tipo de comunicação e comportamento existente, propondo ações estrategicamente planejadas, assessorando a alta administração, facilitando a realização de trocas (relacionamento) e auxiliando na resolução de conflitos.

$\mathrm{Na}$ instituição/organização, por meio da comunicação e da observação do relacionamento dos seus atores institucionais e destes com seus diversos públicos, será possível compreender qual o tipo de cultura existente. Citem-se aqui algumas das muitas definições de cultura organizacional.

Maria A. Ferrari (2009, p. 148) afirma que "é um conjunto de estruturas, representações e significados, negociados constantemente pelos indivíduos e grupos, e por meio dos quais eles interagem socialmente com base na interpretação que fazem da realidade organizacional". João Curvello (2010, p. 254) cita a definição de cultura organizacional de Edgar Schein (1986):

Conjunto de pressupostos básicos que um grupo inventou, descobriu ou desenvolveu ao aprender a lidar com os problemas de adaptação externa e integração interna, e que funcionam bem o suficiente para serem considerados válidos e ensinados aos novos membros como a forma correta de perceber, pensar e sentir em relação a esses problemas.

Segundo Fernando Motta (1997), comunicação e cultura se inter-relacionam - uma influencia a outra. Se, por um lado, a comunicação é um elemento fundamental da cultura, sem a qual esta 
não existiria, por outro lado, os meios de comunicação estão fortemente condicionados a um determinado contexto cultural.

A forma como a instituição/organização se relaciona e se comunica com seus diversos públicos irá definir a sua cultura. Assim, segundo Maria Helena Weber (2009, p. 71) a comunicação organizacional "é o resultado de todas as ações institucionais, promocionais e mercadológicas utilizadas pelas organizações para gerar comunicação, apoio, visibilidade e imagem pública".

Kunsch $(2010$, p. 57) ressalta que

a valorização das pessoas nas organizações deve ser um parâmetro determinante para a produção da comunicação organizacional. As organizações saudáveis, que consideram a qualidade de vida do trabalhador e se preocupam de forma responsável com as consequências de sua comunicação, certamente são as mais criativas, produtivas e admiradas por seus públicos.

De acordo com Paulo Nassar (2003, p. 27), "embora as dificuldades existam em todas as empresas, naquelas em que as pessoas se comunicam mais e melhor, os problemas dificilmente viram crises e normalmente já vêm com uma solução". A comunicação assume então uma função vital, transformando-se em um ativo estratégico de gestão.

Não é tarefa fácil gerenciar com eficiência todo o processo de comunicação organizacional. A comunicação, como um bem intangível, muitas vezes é colocada em xeque e as ações desenvolvidas na instituição/organização ficam em segundo plano. Portanto, tornar o intangível quantificável é o grande desafio da comunicação.

A PNH considera a importância da utilização da pesquisa como instrumento para conhecer o grau de satisfação do público interno e externo, incentivando a pesquisa de satisfação como forma de escuta diferenciada.

Portanto, a pesquisa que recebe o incentivo da Secretaria de Estado da Saúde tem como objetivo estabelecer um canal direto de comunicação. Por meio dele será possível obter informações úteis para auxiliar no aperfeiçoamento da gestão, na capacidade de tomar decisões, na proposição de ações adequadas e, assim, melhorar o atendimento prestado à comunidade (Brasil, 2007).

Segundo Rios (2009), a humanização reconhece o campo das subjetividades, da comunicação e do diálogo como instâncias fundamentais para melhor compreensão dos problemas e para busca de soluções compartilhadas. Considera também a importante aliança da competência técnica e tecnológica com a competência ética e relacional. Assim, fica claro verificar que a sociedade está diante de um novo paradigma de gestão institucional/organizacional, uma nova visão que sai do foco em estruturas e tarefas para o foco em relacionamentos e processos, a gestão participativa.

Podemos fazer um paralelo da gestão participativa descrita acima com o formato de organização flexível descrita por Manuel Castells (1998). Esse autor aborda as interconexões das empresas 
e destaca que existem duas formas de flexibilidade organizacional: o modelo de redes multidirecionais e o modelo de franquias e contratação de serviços de terceiros. Isso nos faz refletir mais especificamente sobre os modelos de redes, pois no caso dos serviços de saúde verifica-se a importância da organização aberta em rede, para maior eficiência e eficácia do trabalho desenvolvido em termos de gestão de processos.

Kunsch (2003, p. 57) destaca a "organização horizontal", que tem mudado o modelo de gestão para adaptar-se às rápidas transformações econômicas e tecnológicas. A autora cita Castells (1998, p.192):

Essa nova organização desce do pedestal da burocracia verticalizada para atuar em rede, organizar-se em torno de um processo, e não de uma tarefa, promover gestão em equipe, mensurar os resultados pela satisfação do cidadão-consumidor e informar/formar seus empregados em todos os níveis.

Passar do modelo de gestão vertical para o modelo de gestão horizontal apresenta-se como um grande desafio principalmente para o gestor, por estar baseada na descentralização, na diluição do poder de comando e na participação dos diversos públicos envolvidos.

Segundo Kunsch (2003, p. 58), o formato de organização horizontal não é fácil de ser implementado, afirmando ela que há controvérsias ao comparar o desenho organizacional hierárquico-verticalizado com o modelo horizontal, em que este último é melhor que o primeiro e, na verdade, deve-se buscar um ponto de equilíbrio entre as duas formas.

Dessa forma, a construção de uma rede de participação social pode implicar obstáculos e desafios, mas, também, grandes possibilidades.

Considerando que o presente estudo se volta para uma instituição pública, não poderíamos deixar de citar a comunicação pública como uma grande aliada para o sucesso do desenvolvimento das políticas públicas. Curvello (2009, p. 202), citando Pierre Zemor (1995), diz que

seriam funções da comunicação pública: ouvir as demandas, as expectativas, as interrogações e o debate público; informar (levar ao conhecimento, prestar contas e valorizar); contribuir para assegurar a relação social (sentimento de pertencer ao coletivo, tomada de consciência do cidadão enquanto ator social); acompanhar as mudanças, tanto as comportamentais quanto as da organização social.

Mariângela Haswani (2011, p. 86) destaca que a comunicação pública

não se refere somente ao âmbito dos atos normativos, mas também às iniciativas voltadas a favorecer a relação entre cidadãos e instituições, a promover as iniciativas e os serviços oferecidos, assim como valores e imagens de interesse geral. 
A comunicação interna, assim, seria o conjunto de ações que a instituição coordena com o objetivo de ouvir, informar, mobilizar, educar e manter coesão interna em torno de valores que precisam ser reconhecidos e compartilhados por todos e que podem contribuir com a sociedade.

Conforme Haswani (2011, p. 86), citando Mancini, há

dois diferentes campos de ação na comunicação pública: um passivo e um ativo. No primeiro caso, a instituição fica à mercê da demanda, dos controles e das verificações que sujeitos externos queiram fazer. Não intervêm ativamente na produção das notícias, limitam-se a aplicar e salvaguardar a maior "transparência" sobre seu trabalho. No segundo caso, é a própria instituição que promove um fluxo comunicativo externo, veiculando conhecimento, mas também intervindo, ou se aproximando de intervir, sobre percepções e sobre comportamento de seus referentes.

Conforme assinala a autora, "a informação (sempre) e a comunicação (quando houver demanda) são instrumentos de garantia dos direitos fundamentais (individuais e sociais) nos estados democráticos (de direito, sociais, cooperativos)" (Haswani, 2011, p. 22).

\section{RELAÇÕES PÚBLICAS}

Considerando que a Política Nacional de Humanização $(\mathrm{PNH})$ tem como proposta trabalhar o relacionamento e a melhoria na gestão da instituição, podemos afirmar que isso diz respeito à principal função das relações públicas. A humanização trabalha a gestão permeada por três elementos básicos: a comunicação eficiente e eficaz, o relacionamento e o estabelecimento de vínculo de confiança. Para Kunsch (2003, p 106), "o verdadeiro trabalho de relações públicas é aquele que, além de informar, propicia o diálogo. E isso só é possível na comunicação bidirecional". Maria José da Costa Oliveira e Silvana Nader (2006, p. 104) escrevem que

vale lembrar que relações públicas, como uma atividade voltada ao equilíbrio entre os interesses de organizações e seus públicos, têm diante de si um cenário social, político e econômico que exige seu posicionamento claro na assessoria às organizações sobre o papel social que devem desempenhar, visando colaborar com as ações de interesse público.

Implementar a política de humanização em uma instituição não é tarefa fácil, pelos seguintes motivos: primeiro, porque o termo humanização já traz de forma oculta uma crítica, havendo a necessidade de disseminação do conceito para compreensão de todos os envolvidos. Portanto, suas ações devem ser desenvolvidas ao longo do tempo de forma sistemática e contínua, a partir de uma visão holística. Segundo, por envolver mudança de atitude e comportamento na rotina de trabalho. Dentro dessa filosofia tão ampla e aparentemente inalcançável, é preciso trabalhar métodos e caminhos planejados de forma estratégica, medindo o impacto da mudança no processo de trabalho que deve ser mensurável. 
A política de humanização sendo de formação eclética e multidisciplinar, na área da saúde apresenta um amplo horizonte para que o profissional de relações públicas atue posicionando-se como estrategista de comunicação e relacionamento. Diz Kunsch (2003, p. 245) que

não basta pautar-se por ações isoladas de comunicação, centradas no planejamento tático, para resolver questões, gerenciar crises e gerir veículos comunicacionais, sem uma conexão com a análise ambiental e as necessidades do público, de forma permanente e estrategicamente pensada.

Assim, avaliar o ambiente interno e externo da organização é de fundamental importância. Essa análise pode ser feita, de acordo com Rozeli Arbaiter (2010), por exemplo, por meio da matriz denominada swot, sigla originada do inglês para strenghts, weakenesses, opportunities e threats. O objetivo dessa análise é definir estratégias para manter pontos fortes, diminuir a intensidade dos pontos fracos, aproveitando as oportunidades e protegendo-se das ameaças.

A matriz swot foi elaborada para sintetizar os cenários, estudo de mercado e análise competitiva. Assim, consolidam-se todos os aspectos relevantes do negócio, tanto as situações macroambientais (demográficas, econômicas, tecnológicas, político-legais, socioculturais), quanto os fatores microambientais (consumidores, concorrentes, canais de distribuição, fornecedores) que afetam diretamente a organização.

Depois de realizada a análise, devem-se priorizar os esforços na busca de solução para aqueles pontos que mais afetam negativamente a organização. As medidas têm de ser eficazmente definidas e aplicadas, e todos devem direcionar suas forças para que o objetivo proposto seja compreendido e alcançado.

Utilizando como base os princípios da matriz swot, será apresentado a seguir o cenário do Hospital Universitário da Universidade de São Paulo, fazendo-se uma análise crítica sobre a possibilidade de implementação da Política Nacional de Humanização - HumanizaSUS.

\section{O HOSPITAL UNIVERSITÁRIO DA UNIVERSIDADE DE SÃO PAULO (HU-USP)}

Ligado a uma das maiores universidades do país, o HU-USP é um hospital-escola regional universitário e de nível secundário. Destina-se a desenvolver atividades nas quatro especialidades básicas: clínica médica, clínica ginecológica e obstétrica, clínica pediátrica e clínica cirúrgica. Mantém contrato de gestão com o SUS para prestar assistência de média complexidade num sistema de referência e contrarreferência, conforme grade de hierarquização definida pelo SUS. É um hospital acadêmico que serve de campo de estágio para alunos de graduação e pós-graduação das unidades uspianas ligadas à área da saúde: Faculdade de Medicina, Faculdade de Odontologia, Faculdade de Ciências Farmacêuticas, Faculdade de Saúde Pública, Escola de Enfermagem e Instituto de Psicologia. 
Inaugurado em agosto de 1981, ele se baseia no tripé assistência-ensino-pesquisa, sendo sua missão desenvolver atividades de ensino e pesquisa na área da saúde e assistência hospitalar de média complexidade, preferencialmente às populações do Distrito de Saúde do Butantã e da comunidade da USP, prestando um serviço diferenciado, com atendimento de excelência (HU, 2012)3.

Localizado no oeste de São Paulo, na subprefeitura do Butantã, abrange as regiões do Rio Pequeno (39 bairros), da Raposo Tavares (27 bairros), da Vila Sônia (44 bairros), do Butantã (20 bairros), do Jaguaré (12 bairros) e do Morumbi (17 bairros), que somam por volta de 425 mil habitantes, segundo informações da Fundação Seade (IBGE, 2010). Além disso, o HU atende a comunidade da Universidade de São Paulo (docentes, servidores e seus dependentes, pesquisadores, alunos de graduação e pós-graduação), que em 2009 era de quase 112 mil pessoas, de acordo com o Anuário Estatístico da USP (USP, 2010). Assim, ele está disponível para um total de quase 537 mil pessoas, que configuram a população assistencial pretendida.

Em termos de recursos humanos o HU dispõe de 1.726 funcionários distribuídos em três níveis: básico (420), técnico (742) e superior (564), contando também com profissionais terceirizados de vigilância, informática e assessoria de imprensa, num total de 147 funcionários.

Sendo um hospital acadêmico, não se poderia deixar de citar o número de alunos nele estagiaram em 2010: um total 1.850, das áreas de graduação, residência e complementação especializada. Nos cursos de aprimoramento, atualização, prática profissionalizante, especialização e difusão, passaram pelo hospital 407 alunos. São dados da Comissão de Ensino e Pesquisa do próprio hospital. Ressalte-se que esse público interno, formado por 4.130 pessoas, entre colaboradores e alunos, é um público estratégico, como potencial agente multiplicador da $\mathrm{PNH}$ no HU e em toda a rede de assistência à saúde da região.

A elevada demanda assistencial e o ritmo de trabalho dos profissionais constantemente acelerado levou a alta administração a formar em 27 de agosto de 2009, a Comissão de Acolhimento e Humanização do HU-USP, por meio da portaria HU-S n. 655/09. A comissão é constituída por uma equipe multidisciplinar, que, após uma escuta e observação atenta e crítica, delineia planos e projetos de ação.

Em 25 de abril de 2011, enfim, foi criado o Serviço de Acolhimento e Humanização do HU-USP (SAHU), com a finalidade de: assessorar a alta administração e as diferentes áreas no que se refere à política de humanização; disseminar essa iniciativa; efetuar pesquisas de satisfação e de avaliação de resultados, monitorando o impacto da divulgação feita para dar visibilidade às ações

\footnotetext{
${ }^{3}$ Ver o portal da instituição: http://www.hu.usp.br.
} 
realizadas. O objetivo que se tem em vista outro não é senão aprimorar a atividade e consolidar a imagem da instituição, visando obter, consequentemente, seu credenciamento como "hospital humanizado", via Secretaria de Estado da Saúde. Uma longa caminhada, repleta de desafios, ainda continua aberta pela frente.

Refletindo sobre o cenário, a comunicação e a cultura existente no HU-USP, apresentamos a seguir, em forma de tabela, a análise swot realizada, com base em Rozeli Arbaiter (2010), avaliando as forças e fraquezas, bem como as oportunidades e ameaças percebidas. Isso pode levar a identificar pistas para se pensar em estratégias de transformação e ações que viabilizem o processo de implementação da Política Nacional de Humanização no HU-USP.

Tabela 1 - Análise do HU-USP pela matriz swot

\begin{tabular}{|l|l|}
\hline \multicolumn{2}{|c|}{ AMBIENTE INTERNO } \\
\hline \multicolumn{1}{|c|}{ FORÇAS } & \multicolumn{1}{c|}{ FRAQUEZAS } \\
\hline $\begin{array}{l}\text { Hospital acadêmico que tem como mis- } \\
\text { são formar profissionais. (agentes multi- } \\
\text { plicadores / educação continuada). }\end{array}$ & $\begin{array}{l}\text { Influência de diversas culturas institucio- } \\
\text { nais - HU-USP, hospital acadêmico que } \\
\text { integra seis unidades de ensino. }\end{array}$ \\
- Interesse da alta gestão. & $\begin{array}{l}\text { Ações focadas somente no serviço de } \\
\text { pronto socorro do HU-USP, sem um tra- } \\
\text { balho de comunicação amplo e integrado, } \\
\text { tanto dentro da instituição, quanto no seu } \\
\text { entorno. } \\
\text { nidades da USP e do Butantã no Conse- } \\
\text { Iho Deliberativo do HU-USP. }\end{array}$ \\
$\begin{array}{l}\text { Funcionários que também são usuários } \\
\text { do serviço. }\end{array}$ & \\
Ambiente on-line, como forma de comu- \\
nicação horizontal, propiciando o diálogo.
\end{tabular}




\begin{tabular}{|c|c|}
\hline \multicolumn{2}{|c|}{ AMBIENTE EXTERNO } \\
\hline OPORTUNIDADE & AMEAÇAS \\
\hline $\begin{array}{l}\text { - Apoio do Ministério da Saúde e da Secreta- } \\
\text { ria de Estado da Saúde para implementa- } \\
\text { ção da Política Nacional de Humanização } \\
\text { - HumanizaSUS. } \\
\text { - Ambiente on-line - criação de "caixa de } \\
\text { ferramenta" do Ministério da Saúde para } \\
\text { produção de saúde, saber e subjetividade. } \\
\text { - Trabalho em rede. } \\
\text { - Hospital humanizado recebe tratamento } \\
\text { diferenciado por parte da administração } \\
\text { pública e dos órgãos governamentais. } \\
\text { Ministério da Saúde coloca à dispo- } \\
\text { sição hospitais humanizados para } \\
\text { visitação, apresentando o trabalho } \\
\text { desenvolvido. } \\
\text { - Receber incentivo proposto pelo Minis- } \\
\text { tério da Saúde e pelo Ministério da Edu- } \\
\text { cação - Portaria Interministerial MEC/ } \\
\text { MS n. } 2.400, \text { de 02/10/2007. }\end{array}$ & $\begin{array}{l}\text { - Questões políticas e econômicas de in- } \\
\text { vestimento financeiro na saúde. } \\
\text { - Falta de execução de políticas públicas na } \\
\text { - Falta investimento maior de recursos em } \\
\text { planejamento e gestão de marca divul- } \\
\text { gando as políticas do SUS. } \\
\text { - Questões culturais e de orientação ao } \\
\text { usuário em relação ao tipo de assistência } \\
\text { que um hospital realiza. } \\
\text { Perder os benefícios concedidos ou pro- } \\
\text { postos pelo Ministério da Saúde e pelo Mi- } \\
\text { nistério da Educação. }\end{array}$ \\
\hline
\end{tabular}

\section{CONSIDERAÇÕES FINAIS}

Com base no que se expôs nos tópicos anteriores e na análise pela matriz swot, conclui-se que o Hospital Universitário da Universidade de São Paulo (HU-USP) possui campo fértil para implementação da Política Nacional de Humanização - HumanizaSUS.

Seria sumamente interessante a instituição investir em planejamento de ações de relacionamento e gestão de marca, admitindo um(a) relações-públicas como mais um profissional para os quadros da instituição, o(a) qual teria como tarefa pomover a saúde, contribuindo com seu saber multidisciplinar para explorar a interface entre as áreas da comunicação e da saúde. 
Considerando os fundamentos teóricos das relações públicas, que, segundo Kunsch (2003), têm funções administrativa, mediadora, estratégica e política, apontaríamos as seguintes contribuições possíveis da área para o HU-USP: 1) como funções administrativa e mediadora, a gestão de comunicação e de relacionamento, integrando as diversas áreas do hospital, possibilitando, assim, uma comunicação de mão dupla, num contexto de participação e integração; 2) como função estratégica, a promoção de ações que agreguem valor aos profissionais, à clientela e à instituição, mostrando a importância de cada um, possibilitando uma visão holística do processo, além da mudança de atitudes e de comportamento; 3) como função política, contribuir para o processo de implementação da Política Nacional de Humanização, bem como, também, realizar ações de relacionamento com os equipamentos de saúde e instâncias com o qual o HU-USP se relaciona. As relações públicas teriam um papel relevante em todo o processo, contribuindo enquanto ciência e participando de equipe multidisciplinar no planejamento e na tomada de decisões.

O HU, como instituição acadêmica inserida na USP, cuja missão é a geração e difusão de conhecimento - o que só pode ser conseguido por meio de uma comunicação eficaz e com a participação dos diversos públicos que fazem parte do cenário -,poderia converter-se em modelo de humanização para diversas outras instituições, além da própria Universidade de São Paulo.

\section{REFERÊNCIAS}

ARBAITER, Rozeli. Análise de risco. Disponível em: http://cobben.com.br/cgi-cn/news.cgi?cl=099111098098101110098114 \&arecod=2\&newcod=45. Acesso wn: 17 out. 2010.

BRASIL. Constituição da República Federativa do Brasil, 1988.

Lei n. 8080 de 19 de setembro de 1990. Dispõe sobre as condições para a promoção, proteção e recuperação da saúde, a organização e o fundamento dos serviços correspondentes e dá outras providências. Diário Oficial da União, Brasília, 1990.

Portaria Interministerial MEC/MS n. 2.400, de 2 de outubro de 2007. Estabelece os requisitos para certificação de unidades hospitalares como hospitais de ensino. Brasília: Ministério da Educação e Cultura e Ministério da Saúde, 2007. Disponível em: <dtr2001.saude.gov/sas/PORTARIAS/Port2007/GM/GM-2400.htm>. Acesso em: 28 abr. 2011.

CASTTELLS, Manuel A. A sociedade em rede. Vol. 3. A era da informação: economia, sociedade e cultura. Rio de Janeiro: Paz e Terra, 1998.

CURVELLO, João J. A. O desvendar das culturas organizacionais. In: DUARTE, Jorge; BARROS, Antonio (Org.). Métodos e técnicas de pesquisa em comunicação. 2. ed. São Paulo. Atlas. 2010. p. 253-268. 
. A dimensão interna da comunicação na administração pública. In: Duarte, Jorge (Org). Comunicação pública: estado, mercado, sociedade e interesse público. 2. ed. São Paulo. Atlas, 2009. p. 201-213.

. A comunicação organizacional como fenômeno, como processo e como sistema. Organicom - Revista Brasileira de Comunicação Organizacional e Relações Públicas, São Paulo, Gestcorp/ECA-USP / Abrapcorp, a. 6, n. 10/11, p. 109-114, 2009.

DESLANDES, Suely F. Análise do discurso oficial sobre a humanização da assistência hospitalar. Ciência \& Saúde Coletiva, v. 9 , n. 1, p 22-27, 2004.

(Org). Humanização dos cuidados em saúde: conceitos, dilemas e práticas. Rio de Janeiro: Fiocruz, 2006. p. 33-47.

FERRARI, Maria Aparecida. Os cenários turbulentos como oportunidade de mudança e de realinhamento de estratégias. In: GRUNIG, James E.; FERRARI, Maria Aparecida; FRANÇA, Fábio. Relações públicas: teoria, contexto e relacionamentos. São Caetano do Sul (SP): Difusão, 2009. p. 129-152.

FREITAS, Sidinéia Gomes. Cultura organizacional e comunicação. In: Kunsch, Margarida M. Krohling (Org.). Obtendo resultados com relações públicas. 2. ed. - rev. e atual. São Paulo: Pioneira Thomson Learning, 2006. p. 53-62.

GRUNIG, James E. Definição do posicionamento das relações públicas. In: GRUNIG, James E.; FERRARI, Maria Aparecida; FRANÇA, Fábio. Relações públicas: teoria, contexto e relacionamentos. São Caetano do Sul (SP): Difusão, 2009. p. 17-34.

HASWANI, Mariângela F. Comunicação pública 360 graus e a garantia de direitos. In: Kunsch, Margarida M. Krohling (Org.). Comunicação pública, sociedade e cidadania. São Caetano do Sul (SP): Difusão, 2011. p. 81-97.

HU - Hospital Universitário da Universidade de São Paulo. Portal Disponíel em: <http://www.hu.usp.br>. Acesso em: 28 abr. 2011.

IBGE - Instituto Brasileiro de Geografia e Estatística. Censo demográfico. São Paulo: Fundação Seade, 2010.

KUNSCH, Margarida M. Krohling (Org.). Obtendo resultados com relações públicas, 2. ed. - rev. e atual. São Paulo: Pioneira Thomson Leaning, 2006.

. Planejamento de relações públicas na comunicação integrada. 4. ed. - rev., atual. E ampl. São Paulo: Summus, 2003.

. A dimensão humana da comunicação organizacional. In: KUNSCH, Margarida M. Krohling (Org.). A comunicação como fator de humanização das organizações. São Caetano do Sul (SP): Difusão, 2010.

(Org.). Comunicação organizacional. Vol 1. Historia, fundamentos e processos. São Paulo: Saraiva, 2009.

MS - Ministério da Saúde. HumanizaSUS: gestão e formação nos processos de trabalho. Brasileira: Mistério da Saúde, 2004.

Política Nacional de Humanização Hospitalar. [Online)]. Brasília: Ministério da Saúde, 2003. Disponível em: <www. saúde.gov.br/>. Acesso em: 28. abr. 2011. 
O desenvolvimento do Sistema Único de Saúde: avanços, desafios e reafirmação dos seus princípios e diretrizes.

Brasília: Conselho Nacional de Secretários Municipais de Saúde. 2003.

MOTTA, Fernando C. Prestes. Cultura, cultura organizacional e cultura brasileira. In: MOTTA, Fernando C. Prestes; CALDAS, Miguel P. (Org.). Cultura organizacional e cultura brasileira. São Paulo: Atlas, 1997.

NASSAR, Paulo. Tudo é comunicação. São Paulo: Lazuli, 2003.

OLIVEIRA, Maria José da Costa; NADER, Silvana. S. Relações Públicas na gestão da responsabilidade social: desafio e oportunidade. Organicom - Revista Brasileira de Comunicação Organizacional e Relações Públicas, São Paulo, Gestcorp/ ECA-USP / Abrapcorp, n. 5, p. 96-107, 2. sem. 2006.

PASCHE, Dário Frederico; PASSOS, Eduardo. A importância da humanização a partir do Sistema Único de Saúde. Revista de Saúde Pública de Santa Catarina, v. 1, n. 1, 2008. Disponível em: <http://esp.saúde.sc.gov.br/sistemas/revista/index.

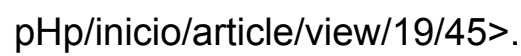

RIOS, Izabel Cristina. Caminhos da humanização na saúde. Rio de Janeiro: Áurea, 2009.

USP - Universidade de São Paulo. Anuário estatístico. São Paulo USP, 2010.

WEBER, Maria Helena. Comunicação organizacional, a síntese. Relações públicas, a gestão estratégica. Organicom - Revista Brasileira de Comunicação Organizacional e Relações Públicas, São Paulo, Gestcorp/ECA-USP / Abrapcorp, a. 6, n. 10/11, p. 70-75, 2009.

Recebido em: 05.04.2012 / Aceito em: 04.06.2012 